\title{
Narrative Support for Young Game Designers' Writing
}

\author{
Kate Howland, Judith Good, Benedict du Boulay \\ Creative Technologies Research Group \\ Department of Informatics \\ University of Sussex \\ Falmer, Brighton \\ $\{$ k.I.howland\}j.good\},b.du-boulay\}@sussex.ac.uk
}

\begin{abstract}
Creating narrative-based computer games is a complex and challenging task. Narrative Threads is a suite of software tools designed to aid young people (aged 11-15) in creating their own narrative-based games as a writing development activity. A participatory design process highlighted the areas where additional support was required, and informed the iterative design of Narrative Threads. The tools are implemented as a plugin to a commercial game creation toolset, and constitute character and object design tools, a branching narrative diagramming tool and an augmented story map view. In this paper, we provide an overview of the design of the tools and describe an evaluation carried out with 14 children over a four-day workshop. The study examined tool usage patterns, and compared games created with Narrative Threads to those created using the standard toolset. The results suggest a number of ways in which dynamic external representations of story elements can support writing activities in narrative-based game creation. Young designers using Narrative Threads wrote more character dialogue, made stronger links between the conversations they wrote and wider game events, and designed more complex characters, compared to those using the standard toolset. In addition to showing how Narrative Threads can support young games designers, the results have broader implications for anyone looking to support storytelling and writing through game creation activities and tools.
\end{abstract}

\section{Categories and Subject Descriptors}

H.5.m. Information interfaces and presentation (e.g., HCI):

Miscellaneous.

\section{General Terms}

Design, Human Factors

\section{Keywords}

Game Authoring; Young People; Design; Narrative; Writing.

\section{INTRODUCTION}

Creating narrative-based games involves writing interactive conversations, designing characters and settings, and structuring a branching plot. Previous research suggests that it is an activity

Permission to make digital or hard copies of all or part of this work for personal or classroom use is granted without fee provided that copies are not made or distributed for profit or commercial advantage and that copies bear this notice and the full citation on the first page. Copyrights for components of this work owned by others than ACM must be honored. Abstracting with credit is permitted. To copy otherwise, or republish, to post on servers or to redistribute to lists, requires prior specific permission and/or a fee. Request permissions from Permissions@acm.org. IDC'15, June 21 - 25, 2015, Medford, MA, USA (C) 2015 ACM. ISBN 978-1-4503-3590-4/15/06 .\$15.00 DOI: http://dx.doi.org/10.1145/2771839.2771858 that many young people enjoy, but which also involves a high level of challenge [7, 26]. Meaning-making in the form of creating linear text (writing) can be challenging enough for young people, and researchers have noted a decrease in confidence in writing from age 11 onwards [23]. Game design may offer a motivating context in which to position writing activities, but writing for games can be very difficult. Making effective use of multiple representational modes (text, audio, graphics) whilst also planning for player interactivity only increases the complexity of the writing task. Although existing commercial game creation toolsets provide the technological means for young people to create their own games, they provide little or no support for crafting the narrative elements of games. Narrative Threads is designed to provide support for narrative-based game creation for young people aged 11-15, through dynamic representations of game and narrative elements. It specifically aims at supporting game creation as a context for writing.

This paper gives an overview of Narrative Threads, and presents an evaluation of its use in a game creation project. First, we explain the background and design process, then give an overview of the tools, describe the evaluation study and present the results. Following this, we discuss the types of support that worked well, and those that were less successful. Finally, we consider the broader implications of these results for supporting storytelling and writing in game creation.

\section{BACKGROUND}

Since Kafai's early work on game creation with young people [17], there has been ever-increasing interest in the benefits of this activity. Although the games-based learning field remains largely focused on game play as a learning activity, researchers are increasingly looking at game creation in a range of learning contexts. Game creation has been explored as a means of introducing children to computing concepts [21, 24], teaching mathematics $[8,18,22]$, and encouraging learners to develop their metacognitive skills $[17,27]$. However, the present research is motivated by work which suggests that game creation has potential to support storytelling and writing $[1,26]$. Despite past debates over the role of narrative in games (summarised in [16]) many popular game genres have strong narrative aspects. There is promising work looking at game authoring as a way for young people to develop storytelling and writing skills, using authoring tools which allow novices with no programming or 3D graphics skills to create impressive $3 \mathrm{D}$ games $[1,2,7,26]$.

The Neverwinter Nights 2 (NWN2) toolset and its predecessor (packaged with the original Neverwinter Nights game), have been used to support young people in creating narrative-based games in a number of research studies [e.g., 2, 3, 6, 7, 15, 25-27, 30]. The NWN2 toolset allows young people without specialist technical skills to create $3 \mathrm{D}$ role-playing games with commercial quality 
graphics. Children can use it to quickly create areas, objects and characters by dragging and dropping GUI elements. Wizards and menus allow users to configure in-game events, including interactive conversations between the player and other characters. Using these tools, children are quickly and easily able to create games with an impressive look and feel.

However, creating games with rich narrative content remains a challenging task for young people. Support for creativity in narrative-based game design, such as ideas generation, task lists and writing branching conversations, is provided through a plugin to NWN2 called Adventure Author [29], and a plugin called Flip allows more complex game behaviours to be scripted using a visual programming interface [12]. However, specific narrative development tasks such as managing a branching plot, designing characters and objects and keeping track of key story locations are not well supported ${ }^{1}$. Narrative Threads was designed to provide this support for young game designers as part of a wider project investigating contextual and software support for the development of writing skills through game creation [10]. The overall goal for the tool was to focus attention on writing and storytelling tasks within game creation, with a view to providing a motivating activity for the practise and development of writing skills.

\section{DESIGN PROCESS}

The design of Narrative Threads builds on theories of narrative and external representation, and was developed through participatory design activities.

Initial observations and interviews with young people at game making workshops suggested that there were ways in which the NWN2 toolset failed to support storytelling and writing. For example, it encourages a reactive approach to character creation, as users drag and drop readymade characters into the game. When asked to explain their game worlds at the end of a game making workshop, some young designers were unsure how characters, objects and areas fitted in to the overall narrative of their games, and it seemed some of these had been added without much thought [10, p. 77].

The toolset represents only the visual 3D appearance of games, leaving the narrative elements invisible. There is also no interface support for complex tasks such as structuring branching narratives. Accordingly, narrative elements may not seem as important to young designers, and our early studies highlighted the scope for additional interface support for narrative [9].

The overall design goals were to make story elements more visible, support complex plotting tasks, and encourage a more reflective approach to the creation of narrative-relevant game elements, without jeopardising the motivating nature of the task [11]. The underlying narrative theory used was Chatman's story \& discourse model [4], and the types of game-narrative the tools aim to support are enacted stories (where the player takes an active part in an unfolding narrative) and embedded narratives (where the player finds out about a narrative indirectly through the game), as per Jenkins' categories [16].

After an initial series of interviews with teachers and young people $[10,13]$, designs were iterated over 4 participatory design

${ }^{1}$ Even experienced professionals can find these tasks challenging. Since the development of Narrative Threads, a tool has been released which provides support to professional games design teams with similar aspects of game and story design (http://www.nevigo.com/en/articydraft/overview/). studies [10, 14]. Design activities included young people creating, revising and testing paper prototypes of tools, as well as giving feedback on the usefulness of tools and the game creation tasks that they found most enjoyable. The following section highlights specific design decisions in the context of individual tools, and includes more details on the participatory design activities employed.

\section{NARRATIVE THREADS: OVERVIEW}

Narrative Threads aims to provide support in two areas: scaffolding the creation of story elements (characters and objects) and improving the visual representation of game-narrative.

\subsection{Story Element Creators}

The story element creator wizards enable users to create and edit characters and other key story elements (objects which have central importance to the narrative, 'story existents' in Chatman's theory). The character creator tool (Figure 1) includes screens for entering basic details, specifying the character's relationship with the player (friendly, neutral, enemy), assigning traits (customisable strengths and weaknesses), writing descriptions and customising appearance.

During participatory design sessions, young people were asked to design their own character creator tools using paper prototyping kits. By discussing their designs in interviews, we discovered that they were keen that users could configure characters in fine detail, but that this was largely limited to appearance-related properties. Participant comments suggested that these elements were motivating because designers liked seeing a visible payoff for their effort in the characters' in-game appearance. In the NT character creator, a persistent 3D view shows the impact of changes, including alteration of appearance and animations indicating the character's behaviour towards the player (e.g. character is shown waving if they are set to friendly). The object creator tools follow the same principles in a simplified form, with a preview window showing the 3D appearance of the object under creation, and text boxes for specifying object name and description.

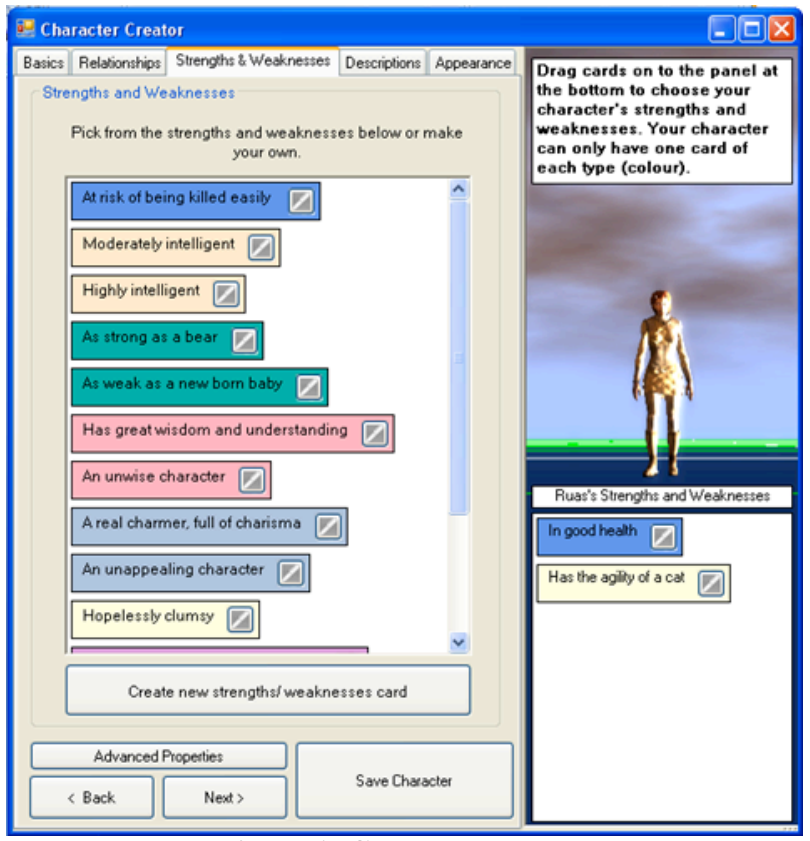

Figure 1: Character creator 
A number of the teachers interviewed wanted to see pupils engaging in more reflective thought when developing game characters. Accordingly, the character creator was designed to encourage a more thoughtful and considered interaction that was more in line with reflective cognition [20]. However, the factors that motivated young designers also needed to be considered. Writing descriptions about a character's personality and backstory were seen as valuable reflective tasks by teachers, but participatory design work with young people suggested that these tasks were not appealing because there was no clear benefit or outcome in the game world. One young designer described skipping a description box because it made no difference to the game. To counteract this, and to ensure that activities which are important to storytelling are seen as important by users, the Narrative Threads wizards give clear feedback for narrative design activities and ensure that there are explicit outcomes for the game under creation. When entering character and object descriptions, users can choose to have the text appear on the player's in-game map, along with a map point showing the location of the object. Underlying character properties can be set by dragging and dropping descriptive phrases relating to in-built parameters that affect the behaviours and abilities of characters (e.g. charisma, dexterity, strength). For example, a low strength score is marked by the description 'As weak as a newborn baby'. Users are also able to define their own descriptive terms and pick the associated trait and score. In this way, text-based descriptions are given a purpose beyond planning.

Once created, characters and objects appear in a story elements panel on the interface and, from that panel, can be added to a game area, edited, or deleted.

\subsection{Visual Representation of Game-Narrative}

In the standard toolset interface, the only visual representation of the game under creation is a $3 \mathrm{D}$ area view. Although game elements (e.g. characters and objects) are visible, there is nothing to indicate whether a given element has a crucial role in the story (performing at least one plot-significant action and thus being a 'character' under Chatman's definition), or has simply been added as scenery (an element of setting). Similarly, there is no visual representation of story events (Chatman's actions and happenings).

Narrative Threads provides two complementary representations of the game-narrative; a branching narrative diagram and an augmented map view. The branching narrative diagram (Figure 2) is a representation of the enacted story in which the player will participate during the game. It shows the key story events and possible narrative paths between them. Embedded narratives may also be communicated to the player through events featured in the diagram. The branching narrative diagram is designed to be used both as a planning tool and as a representation of the storyline as the game develops. The aim was to provide the designer with a visual representation of the narrative paths that the player can follow within the game. This complex information can be hard to conceptualise without external representations to support cognitive offloading [19].

A fully automated diagram creation process was ruled out, partly because of the prohibitive computational complexity, and partly because active construction of the diagram provides an important opportunity for reflection about the developing narrative. However, the participatory design process, which involved young people creating their own diagrams on paper, suggested that it would be beneficial for event blocks to be automatically generated, complete with branching choice points, based on the story elements created. As a result, the branching narrative diagram reflects what the designer has created through blocks representing scenes, and users then compose the diagrams by arranging the blocks and drawing the links. There is also a facility to create custom blocks for events that cannot be automatically generated, and to allow users to plan for future developments where characters or objects have not yet been implemented.

Diagrams are composed by dragging in scenes from the bottom

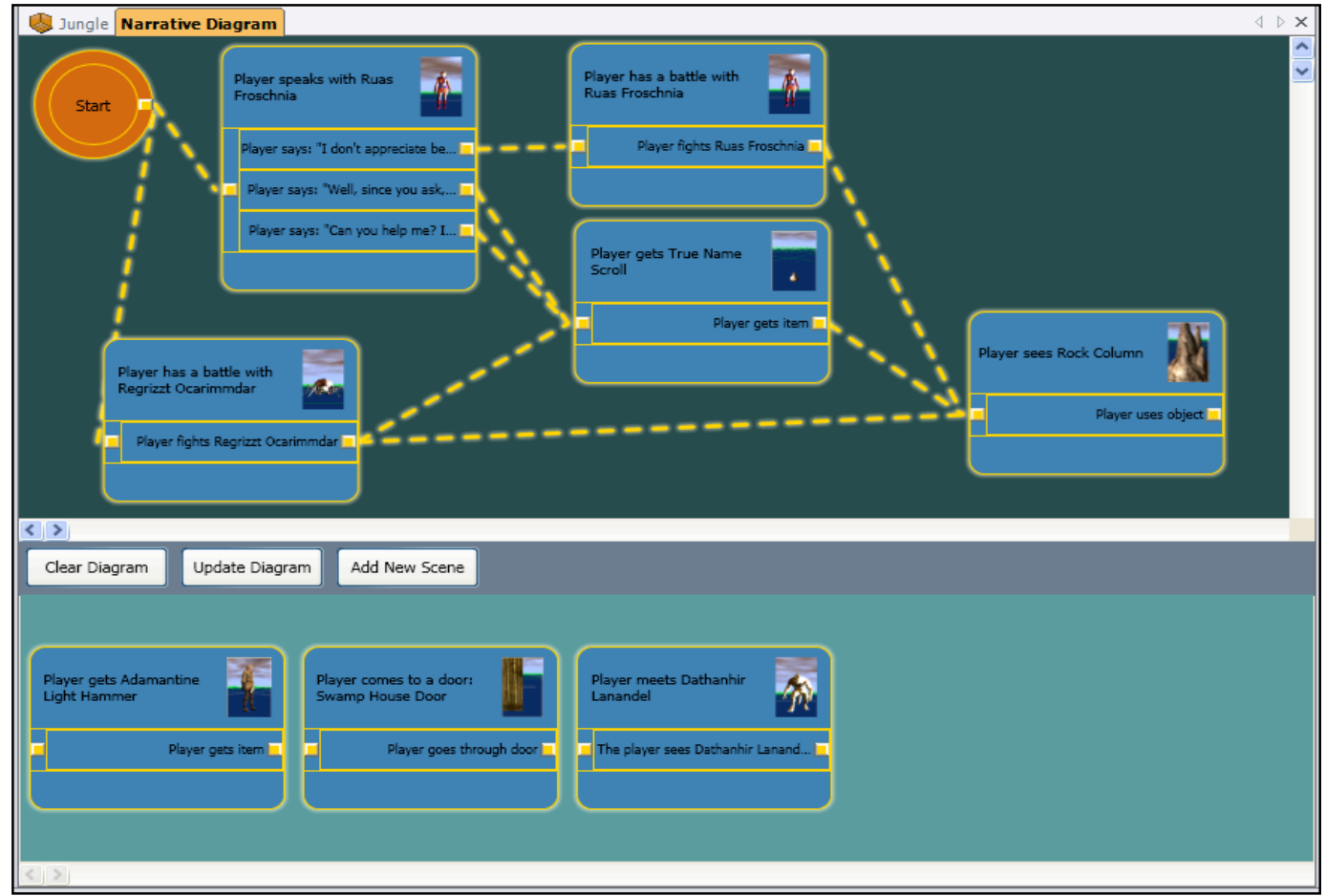

Figure 2: Branching narrative diagram 
panel and drawing connections between scenes by clicking one scene's connection point and linking it to another scene's connection point. Start and end nodes are distinct, and connections can only be made from an end node of one scene to a start node of another scene. The diagram updates as the designer makes changes in the toolset, and nodes are added and removed in line with the story elements created using the creator tools.

The augmented story map view (Figure 3 ) is a modified version of the existing toolset area view. It shows the location of key story elements, and uses icons to indicate which type of story event can happen at that location. For example, hostile characters generate a crossed-swords 'battle' event icon, while connections to other areas are represented by a 'transition' icon with an arrow. Participatory design sessions indicated that young game designers were able to understand these icons, and use them to create accurate maps of story event locations in their own games. The icon designs were developed from low-fidelity prototypes created by target users, with each icon based on the representation that the majority of target users felt was most clear for that category.

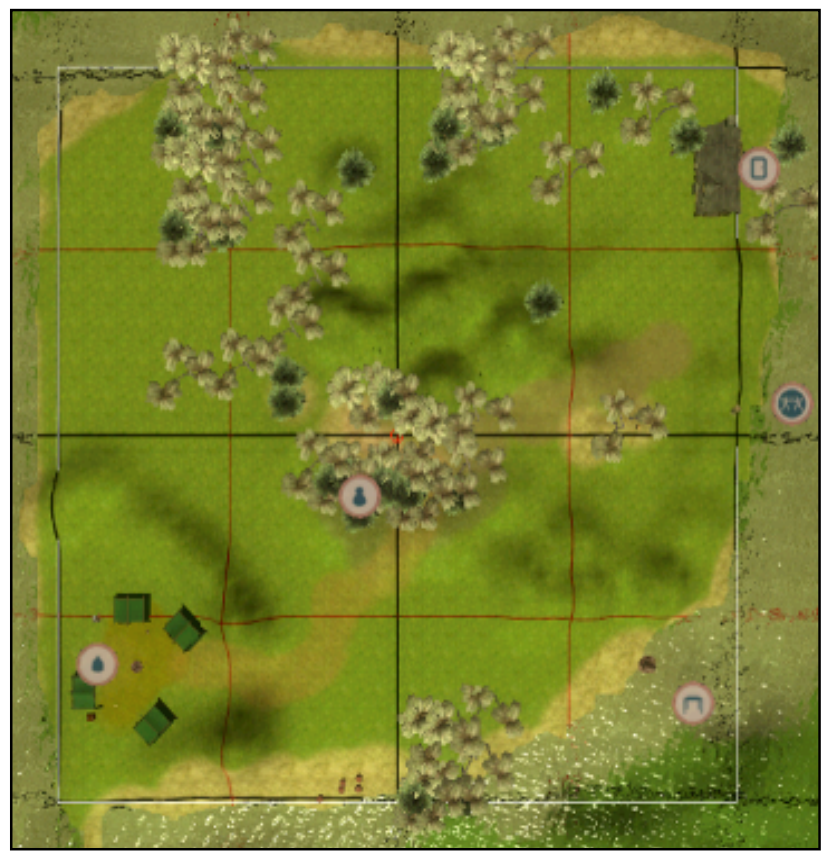

Figure 3: Augmented Story Map

\section{EVALUATION}

The evaluation described here was part of a larger study that compared young people creating games in both a school and a workshop context [10]. The workshop study, described here, was designed to explore how young novice games designers use Narrative Threads over the course of a real game creation project, and to examine the impact of the tools. We were interested in potential influences on the way designers think about their games as well as the games themselves.

\subsection{Method}

\subsubsection{Participants}

Fourteen young people aged 11-15 took part in a game creation project during a four day half-term holiday workshop. Participants responded to advertisements placed online and circulated via local websites and mailing lists, and places were allocated on a firstcome, first-served basis.
Prior to the workshop, participants were divided into two groups of equal size and matched, as far as possible, for age. Two participants who had previously taken part in game creation projects run by the researchers were spilt across groups. One group $(1$ female, 6 male, mean age $=13.14)$ used the NWN2 toolset with the Narrative Threads plugins (referred to hereafter as 'NT toolset'). The other group ( 7 male, mean age $=13)$ used the toolset without Narrative Threads (referred to hereafter as 'basic toolset').

\subsubsection{Procedure}

The groups worked in separate rooms on a university campus. The first author led the NT toolset group and the second author led the basic toolset group, but researchers moved between groups over the course of the workshop. Both groups also had access to the visual programming language Flip, as a plug-in to the toolset [5].

At the start of the workshop, participants were asked to write a review of a game they had played recently ${ }^{2}$. This allowed us to assess whether there were any major differences between the groups in terms of motivation and ability to write. The review took the form of a multimedia slide show with text and images.

Taking into account breaks, and time spent on the review activity, participants spent approximately 21 hours on the game creation project. Participants were given regular toolset demonstrations which took approximately 4 hours, leaving around 17 hours for independent work on games with additional support as required. The NT toolset group received two demonstrations on NT tools: one showing how to use the character/item creators and the story icons functionality, and one showing how to use the branching narrative diagram to plan their stories. The basic toolset group were given a demonstration on using the standard toolset properties windows to customise characters and objects in place of the former, and were given guidance on paper-based character planning activities. In place of the branching narrative diagram tool demonstration, the basic toolset group were shown how to draw a branching narrative diagram for their game-stories on paper.

Video recordings were made during the workshop, and notes were made following discussions between the workshop leaders at the end of each day. All participants were interviewed at the end of the workshop. These interviews were audio recorded and later transcribed verbatim. The game modules created by the young people were collected at the end of the workshop, along with log files of the interactions with Narrative Threads.

\subsection{Results}

\subsubsection{Pre-Study Writing Task}

Both the quantity of words written and the quality of the pieces were analysed. There was a trend for the basic toolset group to write more (a mean of 266.2 words compared to 246.3), but there was no significant difference in word counts between the groups $(\mathrm{t}=0.32, \mathrm{n}=13, \mathrm{~ns})$.

To examine differences in writing quality, a trained English teacher with experience teaching the target age range was asked to mark the game reviews. An existing marking scheme was used, in the form of the UK National Curriculum assessment framework for English (an ordinal scale). The teacher had no involvement in the study and was blind to the conditions. A Mann Whitney U test revealed no significant difference between the groups on the pre-

\footnotetext{
${ }^{2}$ One participant arrived late and did not complete this task.
} 
study writing task $(\mathrm{U}=8.5, \mathrm{Z}=-1.85, \mathrm{n}=13$, ns), although there was a trend for work by the NT toolset group to be marked slightly more highly

\subsubsection{Narrative Threads Usage Logs}

Log data were collected for the Narrative Threads group, recording the time spent using the active tools (the character and object creators and branching narrative diagram - the augmented map view and story elements panel are passive representations which do not have recordable usage time) and the key actions carried out within each tool.

Of a total of approximately 17 hours spent working on games, the mean usage of the active Narrative Threads tools was 1 hour 54 minutes. The greatest amount of time was spent on the character creator tool, with a mean usage time of 1 hour 24 minutes and a mean of 35.42 uses. Participants created an average of 11.4 unique characters, 6.28 character descriptions and 3.42 back stories. A mean of 32.7 strength and weakness cards were added, and a mean of 5.28 custom strength and weakness cards were created with accompanying descriptions and property settings.

The object creator tools were not as widely used. A mean of 12 minutes was spent using object creators, with a mean of 6 objects created per person using these tools, and an average 0.85 object descriptions written. The branching narrative diagram tool was used for a mean of approximately 8 minutes. On average participants used it 1.14 times, and added an average of 11.71 links, 8.71 scenes and 3.57 custom scenes. The logs showed that all of the workshop participants kept the augmented story map view turned on for the duration of the workshop.

\subsubsection{Observations and Interview Data}

All participants reported finding the character creator tool useful and easy to use. A number of interviewees commented that it was particularly useful for creating the player characters. One interviewee said of the tool "I relied on that a lot" and mentioned the strengths and weakness cards in particular, saying that they made the process "...very easy, it's just dragging things into... and it's really easy to create one, you just type in a sentence and drag the bar on and choose it". Participants reported spending most time on the basics screen or the strengths and weaknesses screens, while the appearance screen was also mentioned a number of times. One participant said that he found it particularly helpful to be able to scroll through appearances in the tool. Another interviewee mentioned spending considerable time on the descriptions for the most important characters.

We observed that the character creator tool was used slightly less by the end of the week. However, participants still tended to use the wizard to start the character creation process, going on to fine tune characters in the toolset properties window. Having the key characters appear in the story elements panel seemed to be important to the young game designers, as an occasional bug where they temporarily disappeared caused concern (despite there being no effect on the characters in the game).

The interviews confirmed that users were happy to keep the augmented story map view switched on. Some participants said that the icons were useful, particularly for diagnosing problems such as conversations and doors incorrectly connected. Many users said that they had not really noticed the icons, but some felt they might be useful when designing very large areas.

Observations of the narrative diagramming tool usage were in line with the log findings. All participants used the tool after the initial introduction, some for only a few minutes, others for a longer period of time, with only a few sightings of the tool being used throughout the rest of the workshop.

The interviews allowed us to explore why the narrative diagram tool was not used extensively by participants. One participant reported that he found the tool somewhat useful for planning, but did not return to it as he got distracted with fixing specific problems as he went on. An interesting explanation for why the tool was not useful came from one participant who said that it "...felt like it was pointing out the obvious because I'd already done these things when I'd been putting it together, and I had to create this sort of thing to show what I was doing". He also noted that he would rather use paper for planning purposes, a view echoed by another participant. It was clear that many participants saw it solely as a planning tool rather than also as a way of thinking about the on-going development of the plot. One young designer said that he already had a clear idea of what he wanted to do, and his plot did not include many branches so he had not needed it. Another said that she does not "really do that well with planning stuff out..." Two participants described feeling slightly confused by the branching narrative diagrams. One said that he thought this was because it was introduced too early in the process for him and he had not yet planned out the beginning of his game. The other said that he found the tool something of an obstacle, and preferred to just keep his ideas in his head and felt that if he forgot them, then they were not that important. However, one interviewee said that he did find the tool useful, and used it to plan out parts of the game that he had not yet implemented. He also said that he went back to use the tool again after the initial introduction, and found it easy to use.

Participants were asked to give an account of their games during the interview. We started with the broad prompt: "Tell me about your game", a question which leaves it open to participants to decide whether to talk about the narrative, the gameplay, the setting, or other elements, depending on what they think is most important. Four out of seven basic toolset users and seven out of seven NT toolset users chose to describe a game-narrative in which the player takes part. For example, one NT user said:

"You play as this character - Lodin - who is a soldier in this army and... the kingdom has been torn apart by this unknown terror that's been attacking all the lands. A nearby town loses contact with this barn [and] you and your friend,Scott are sent to try and find out what it is. And you realise the terror is this dark wizard and his army of evil creatures..."

A basic toolset user who described a narrative said:

"You wake up in the morning, and you can't remember where you've been or what you've done, so then you talk to a blacksmith and he tells you you should go up to the tavern to find out where you are, because you were there the night before, but, you got into a bar fight...But he rescued you, and then you go over there and there's the landlord [who] tried to kill you, but you have to have a massive fight with him, and... he's been keeping your sister captive."

The three basic toolset users who did not mention narrative elements described discrete features of their games, for example:

"I've created quite a lot of areas, most of them are interior, I've got a forest, which is a forest and then I've got a village... and then I've got all the interiors, which are the houses, the blacksmiths... the bar and all that. I've got a few conversations, a couple of hostile creatures around all the forest and I'm going to put some into the village." 
When given a similarly broad prompt to "Tell me about the main characters in your game" one of the basic toolset users, and all seven of the NT toolset users chose to talk about personality, traits and goals of their game characters. For example, one NT toolset user said:

"Scott... as a young boy he wanted to be a soldier and he was always getting his reluctant sister to do sword fighting with him, with wooden swords and things, and he'd been doing that, and... he's quite noble, he's very loyal..."

The only basic toolset user who made any mention of personality said of one character:

"That big demon guy...he has body odour - that pops up in the conversation, and your character will either say "We're not here to discuss your odour" or "Yeah I know, I think it's that armour, it really chafes as well" and he's pretty demonic."

The other six character descriptions from this group were briefer and did not refer to personality, traits or character goals, for example, one basic toolset user said:

"[There is] just the player...fighting a lot of different creatures and starting fights. There's rats, which are... he kills them in one hit. Going to... the dragons, which are very hard to kill."

\subsubsection{Game Ratings}

To examine of the quality of the games, we commissioned a teacher to act as an independent rater. The teacher had experience with running game creation projects with the NWN2 toolset, but no involvement in the study or awareness of the conditions. The rater was given a criterion-based rating scheme, which comprised categories for key elements in narrative-based games. Each category has a question and descriptors which give guidance on how to rate the game out of 10 , for example, in the first category the rater is asked: How well does the designer guide the player on where to go? The descriptors for this category are: 0: The player is given no idea about where the interesting elements of the game are or how to find them. 5: The player is given some clues as to which way they should go, but they might be hard to understand or the clues themselves might be hard to find. 10: The player is guided in subtle but clear ways which are seamlessly integrated into conversations or area design elements such as paths or gaps in mountain ranges etc. The other categories used were: storyline; visual interest; player purpose; meaningful choices; interesting characters; dialogues; imaginative elements; challenge level. Full details of the criteria are given in [10, pp. 156-160].

Mann Whitney U Tests carried out on the data ${ }^{3}$ indicated a significant difference between the two groups on the total rating for each game $(U=8, Z=-2.11, n=14, p<0.05)$, with the games created using Narrative Threads rated more highly. There were also significant differences on the sub-categories of Visual Interest $(U=9, Z=-2.14, n=14, p<0.05)$ and Challenge $(U=7.5$, $\mathrm{Z}=-2.21, \mathrm{n}=14, \mathrm{p}=0.05)$, with games created using Narrative Threads again rated more highly. There was also a trend for the games created by the NT toolset group to be rated more highly on every other sub-category.

\subsubsection{Game Summaries}

Whilst the game ratings gave a high-level overview of the quality across groups, there was a need for a more detailed analysis of a subset of games to help us understand the factors that led to the

\footnotetext{
${ }^{3}$ Non-parametric tests were used because the data violated the assumptions of normality and equality of variance.
}

ratings. The first author played the games from each group that were rated first, third and sixth out of seven, and wrote descriptive summaries to provide a qualitative account of the games. Summaries of the six games are given in this section, using participant pseudonyms.

Richard's game (created with basic toolset) - ranked $1^{\text {st }}$ in basic toolset group, ranked 4th across both groups.

Richard (13) created a game with some nicely designed areas but little in the way of storyline. Interestingly, when prompted to describe the story of his game in the interview, Richard said that the player's town has been burnt down and destroyed by a creature, and that the player has to find the creature, and also his family, who have gone missing. However, no elements of this story are evident in the game. There is a town area, which seems quite empty, but no evidence of a fire. The one person in that area who the player can speak to makes no mention of a disaster befalling the town, or of the player character's family.

The player is not given a clear purpose in the game, but the implied purpose is that of collecting treasure. Wooden signs near the start point encourage the player in a certain direction. If the player then battles through some hostile creatures, they get to a house where treasure is being guarded by some zombies. Along the way, a dragon and a spider give some useful information, such as the locations of the hostile creatures and treasure. The characterisation is quite weak, as we don't get any sense of what these characters' relationship is to the player, why they are helping, or what they think of him. Finally the player reaches a sparse village with two buildings. One building is empty, and in the other we meet a blacksmith who tells the player to go and find his twin, the other blacksmith. It is possible that the story Richard described in his interview was meant to unfold after this point, but that this was as far as he got.

Richard appears to have focused on setting challenges for the player, such as fighting the zombies to gather the treasure, rather than connecting up the encounters into a coherent story. The player is guided reasonably well through paths and signs, although the hilly terrain made the path hard to discern in places, and no explicit information is given about where the player should be heading or what they should be doing.

Alan's game (created with basic toolset) - ranked $3^{\text {rd }}$ in basic toolset group, ranked 9th across both groups

Alan (12) had difficulty getting his story ideas across in his game, and also in setting a reasonable challenge level for players. Although he explained in his interview that the game is about rescuing the player's brother, there is no mention of this in the game, either in dialogue or by any other means. There is in fact only one conversation in the game, which comes right at the start when the player speaks to a woman standing nearby. In this conversation the player can ask for help getting to "the boat on the other side", which results in the woman, and some of the other characters standing nearby, joining with the player to fight alongside him. There is no attempt at characterisation of the player or the other characters.

It is hard to know where to go in this game, as the starting area is very large and there aren't any pathways, signposts, or directions from characters. The boat mentioned in the conversation is not visible from the starting point, but becomes so when the player gets nearer. It is also very hard to travel through the area, due to a large number of hostile creatures, such as bears and spiders. There are many items which can be picked up, mainly weapons and armour, but their presence is not explained. If the player makes it 
to the boat, there is no sign of what to do, and no one to talk to or interact with. However, there is a house a short distance away that the player can enter. This is an internal area with some items which suggest it is a domestic space, but also some incongruous items (an alchemical bench, a pile of gold).

There are no characters in this area, but there are some items that can be picked up, mainly staffs to be used as weapons. This appears to be as far as the designer got with the game. Game play is quite poor due to the very high number of hostile creatures, and player guidance is also weak, with the player given little idea of where to go and what to do.

Kofi's game (created with basic toolset) - ranked $6^{\text {th }}$ in basic toolset group, ranked $13^{\text {th }}$ across both groups

Of all the interviewees, Kofi (12) gave by far the most detailed description of his game's storyline, but he struggled to implement his ideas within the game in a way the player can understand. The independent rater had such trouble navigating the area that she believed there were no conversations, and as a result understood nothing about the story. This led to a lower rating than might have otherwise been appropriate. Kofi explained that the player's goal is to help save the land of Am, which has been thrown into chaos since 'The Entity' came and turned all creatures evil except those who had 'the Orbs'; mystical objects that were subsequently stolen. The player can get this information from a man called Mou, if they manage to find his house (the expert rater could not). The player's goal is to find the orbs and return them to bring peace back to the land. The storyline is very imaginative, if the player is able to find out about it.

The quest involves fighting through a large number of the 'evil' creatures to reach a boat, which will take the player to another continent where one of the orbs is to be found. Many hostile creatures protect the orb in this new area, but it is possible to reach it. The orb is meant to teleport the player back to the original area once retrieved, but this behavior had not been implemented by the end of the workshop.

Lack of clear player guidance lets down the imaginative storyline, making it easy to miss the whole purpose of the game. Game play is very difficult, as the two battles within the game are impossible to win, although it is possible to run away from them.

James's game (created with NT toolset) - ranked joint $1^{\text {st }}$ in NT toolset group, ranked joint $1^{\text {st }}$ across both groups

James (13) created a game which tells the story of a young person on the cusp of adulthood being faced with the realities of the world and the necessity of getting a job. A humorous exchange with his father leads to him leaving the family farm to head for the local 'mage station' where his father has secured him his dream
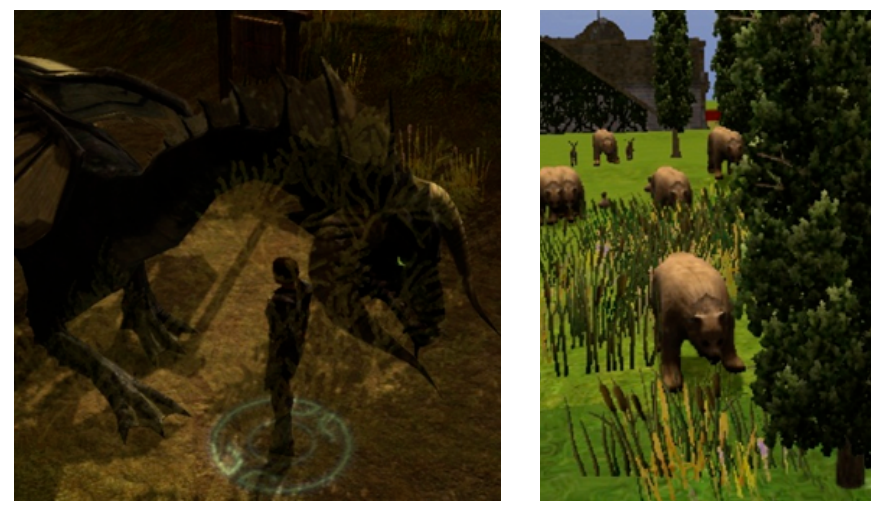

Figure 4: Screenshots from games, L-R - Richard, Alan, James and Karen's games job. Along the way the player meets a 'dodgy merchant' keen to relieve him of his money, comes across dangerous creatures, and after fighting off a group of vicious beetles, is 'spotted' by a talent scout from the aforementioned mage station. In his interview James explained that the player was then due to come up against spies from a rival group who would attack him, but he did not manage to implement this within the timescale.

James's game has some humorous and touching moments. The player character is developed in a very interesting way. The game play was well designed, with battles of increasing difficulty placed along the way, in line with the unfolding story. James guides the player well through his game, using area design elements such as pathways in conjunction with dialogue content and pop-up text boxes.

Karen's game (created with NT toolset) - ranked $3^{\text {rd }}$ in NT toolset group, ranked $3^{\text {rd }}$ across both groups

Karen (13) said in her end of week interview that she had based the game on a story she was currently writing. She explained that the player takes the role of a young female adventurer, Nicola, and that there is a "noble kid" who wants to become an adventurer, who the player ends up taking on as an apprentice. From there, she explained, the story continues with the pair taking part in adventures to find valuables for a woman called Gloria. The adventurer also meets up with her sister, who eventually betrays her, leading to an on-going battle between the two. Karen had only implemented the game up to the point in the story where the player is due to meet Gloria.

The attention to detail in the game is impressive. Karen put a lot of effort into introducing the character of the noble, explaining the player's persona and conveying the story setting. The dialogues make good use of different dialects to show character background, and the visual design of the characters fits well with their traits. Karen paid little attention to game play, however. In the interview she reported plans for quests and battles, but did not have time to implement these. Player guidance was achieved successfully through a combination of textual instructions and area design.

Chris's game (created with NT toolset) - ranked $6^{\text {th }}$ in NT toolset group, ranked 7 th across both groups

Chris (14) created a game in which the player must travel down to hell to defeat the evil overlord of the land. This story comes through at points within the game, as well as in the end of week interview, but the narrative and goals are not conveyed to the player as coherently as in some of the other games. Along the way the player meets a number of other characters and attempts to persuade them to join him in his quest to defeat the overlord. They all agree to help in principle, but we see little action from these
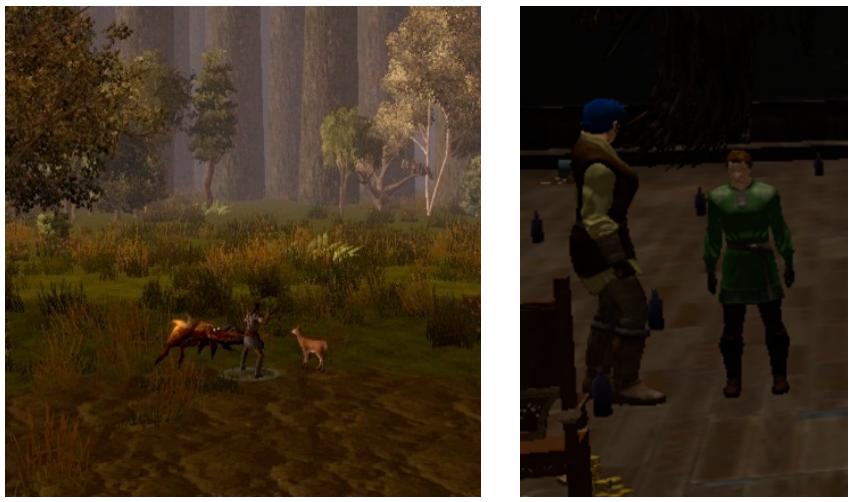
commitments within the game. Chris did not manage to implement the final showdown with the overlord within the timescale of the workshop.

There was some effort put into characterisation, but we don't get a strong sense of the player character's personality beyond what we learn from some short conversations in which we find him determined to defeat the overlord and making belligerent responses to most characters. The game has humorous moments, such as when the player realises that the drunk man in the inn, whose help they need for the quest, will only speak sensibly to them after being given the 'potion to cure hangovers'.

The area design is reasonably effective, with the hell scenes taking place in near darkness, and including burning buildings and a lake of fire. Player guidance is mostly well done, but it is hard to know where to go when the game starts, and it would be easy for the player to miss an important encounter in this area. Game play was fairly well implemented, except for the point at which the player comes across a group of zombies who are impossible to harm.

\subsubsection{Game Statistics}

An automated game analysis tool was created to produce frequency counts of key elements in all fourteen games. The elements counted were: game areas (levels); game objects; inventory items; characters; friendly characters; hostile characters; characters with conversations; conversation word count; total scripts; conversation action scripts and conversation condition scripts. The scripts are those created using the Flip programming language, which are used customise interactions in the game. Conversation action scripts make an action happen when a character says a line (e.g. character says "Here you are" and the player is given a potion), and conversation condition scripts mean that a line is only said if a specified condition is true (e.g. character only says "So, you've defeated the dragon" if the dragon character is dead).

Mann-Whitney U Tests carried out on the counts ${ }^{4}$ revealed few significant differences between the groups, the exceptions being that the NT toolset group created significantly more areas in their games $(U=6, Z=-2.43, n=14, p<0.05)$, wrote significantly more words within conversations $(\mathrm{U}=8, \mathrm{Z}=-2.11, \mathrm{n}=14, \mathrm{p}<0.05)$ and added significantly more conditions to conversation lines $(U=7$, $\mathrm{Z}=-2.61, \mathrm{n}=14, \mathrm{p}<0.001)$. The last result was highly significant. Five of seven NT users added conditional scripts to conversations, compared to none of the basic toolset users.

\section{DISCUSSION}

Usage of Narrative Threads was examined through system logs, observation and interviews. The character creator was by far the most widely used tool, and the one reported by users as being most helpful. The strength and weakness cards were frequently used to define characters' traits and properties, and character descriptions were also written fairly frequently. There were nearly twice as many descriptions as back-stories written, suggesting that the in-game payoff from writing descriptions, which appeared as text on the player's map, may have successfully encouraged users to write them (back-stories had no equivalent in-game representation). When asked to describe their characters in interviews, all NT users mentioned character personalities or traits, compared to only one basic toolset user. This suggests that

\footnotetext{
4 Non-parametric tests were used because the data was not normally distributed.
}

young designers may create characters with more depth and more complex personalities when scaffolded by a character creator tool, in contrast with dragging and dropping readymade creatures into their game in the basic toolset.

The branching narrative diagram tool was not used for as long as the character tools, and most participants used the diagram on only one occasion. This was disappointing, as we hoped that participants would return to the narrative diagramming task throughout the game creation process. Through interviews we learned that some participants felt that constructing their own diagrams was extra work without a clear payoff. Some preferred to plan on paper, and there were no accounts of the tool being used as a way of checking the narrative paths that were possible in the game.

Our participatory design studies indicated that it was important for reflective and effortful activities to have a noticeable outcome in the game. Although this was implemented in the creator tools, it was not possible to carry this through to all of the other tools. It is notable that the character creator tool, which most fully achieved the goal of relating tasks to in-game outcomes, was by far the most widely used. In contrast, the branching narrative diagram, which required considerable user input with no explicit in-game outcome, was used much less frequently.

When considering game statistics, the NT toolset group wrote significantly more words within conversations, as well as adding significantly more scripted conditions to conversation lines, and creating significantly more areas. The higher conversation word count is of particular interest, given that one of the key aims of the wider Narrative Threads project was to encourage the practice of writing skills through game creation. Considering the trend for the basic toolset group to write more on the pre-workshop review task, there is some evidence that Narrative Threads may encourage designers to write more dialogue. The significant difference in number of conditions on conversation lines is also interesting, as it suggests that NT users are more likely to create complex conversations which are more tightly linked to other narrative events.

The expert analysis also revealed some significant differences between the games created with and without Narrative Threads. The NT games were rated significantly more highly overall, with a trend for NT games to be rated more highly on all categories. Interestingly, when asked to describe their game in interviews, all seven NT users talked about the storyline, compared to four of seven basic toolset users. Although the difference is not as striking as with the character descriptions, this may be an indication that the use of NT encouraged designers to develop a game with a strong narrative.

It is also interesting to note that the basic toolset users who described storylines in their interviews seemed not to have conveyed much of the content through their games. Both Richard and Kofi described in-depth stories in their interviews, but when the games were played, these were not apparent to the expert rater, and were hard for the first author to identify. This suggests that NT may provide support not only for the development of the storyline, but also for the translation of story ideas into game elements which can be found and interpreted by players.

Given that the narrative diagram was not extensively used, it is likely that any effects relating to more developed or better implemented storylines come from the combination of more attention to character development and the effect of the augmented map view and story elements panel, which made story 
elements visible and, as a result, may have kept these aspects present in designers' minds.

As well as the significant difference in overall expert ratings, there was a significant difference on the sub-categories assessing whether the game succeeded in creating a visually interesting and convincing setting, and creating an appropriate challenge level for the player. This higher setting rating may be linked to the augmented story map view helping designers develop a stronger sense of where the key story locations were, resulting in an improved area design. The higher rating for appropriate challenge may also be due to the augmented map view. The feedback that NT users received regarding the frequency and location of battle events through the story icons may have allowed them to better ascertain whether the challenge level was manageable. Furthermore, it may be that the character creator tool encouraged NT users to create complex characters embedded in a more subtle narrative, rather than simply adding hostile creatures in combat scenes. Further investigation is needed to determine with greater specificity how individual tools contributed to the higher quality narratives created by the NT users.

\section{CONCLUSIONS}

\subsection{Evaluation of Narrative Threads}

Narrative Threads was designed to support narrative-based game creation by scaffolding character and object creation and providing representations of the game-narratives under development. The character creator was well-used and well-liked, whilst the other active tools were used intermittently and only found to be useful by some designers. There were some clear differences in the games created with and without the support of Narrative Threads. As could be expected from the patterns of use, the differences were most evident in game characters. Narrative Threads users wrote conversations for their characters which were significantly longer, and contained significantly more conditions, indicating that their conversations were more tightly linked to other story events. When interviewed, participants who used Narrative Threads were more likely to describe complex characters with personality traits and goals, whereas basic toolset users often described characters only superficially or functionally.

This evaluation is somewhat limited by the relatively small number of participants who used the tool, and further work should examine whether these findings apply on a larger scale. However, the reasonably large number of hours spent on the project over four days adds some weight to the investigation. Additionally, the age-matched groups and results of the questionnaire and review tasks carried out at the beginning of the workshop suggest that the cohorts were well matched in terms of ability.

The evaluation also indicated some areas for improvement for Narrative Threads. In particular, very few participants returned to the branching narrative diagram after the initial use. One approach to encouraging sustained use of this tool would be to tie effort to clear in-game outcomes, a principle which was successfully implemented in the creator tools. For example, in a future design, drawing connections between scenes in the diagram could potentially create transitions between relevant areas, a task which users typically find quite challenging, or create scripts to reflect the behaviours specified by the diagram.

\subsection{Broader Implications}

\subsubsection{Game-making can encourage storytelling and creative writing}

This study shows that, with appropriate support, game making can take the form of a storytelling task in which written text is used alongside other representational modes to create an interactive narrative. Multimodal writing skills were evidenced in most of the games, as well as an understanding of the importance of audience awareness. Being able to put oneself in the player's shoes was an essential ability to develop, as carefully written conversations could be (and in some cases, were) missed due to poor guidance.

\subsubsection{The motivational power of creating $3 D$ narrative-based games comes with a time and complexity cost}

Most young people, across both groups, found that they had not fully implemented their game ideas after a four day workshop. This was largely due to designers having ambitious ideas which took a long time to implement in the 3D game engine. When considering the already complex activity of creating a narrativebased game, the motivational power of commercial quality graphics come at the cost of an additional demand on time, which must be weighed up by educators and researchers considering game creation as a storytelling activity.

\subsubsection{Motivating 'pay-offs' can be harnessed to direct effort towards storytelling tasks}

When creating a valued public artefact, such as a computer game, young people are willing to put great time and effort into activities that they see as contributing to the final product. However, they may spend less time on activities where there is no direct pay-off in the game, such as character backstory, and narrative planning. In some cases, narrative development activities such as writing character descriptions can be tied to in game outcomes. In other cases, this is not possible, and we need to find other ways of supporting young designers to help them see the benefit to their games. For example, regular play testing sessions, in which designers get peer feedback, can highlight areas of the narrative which are not clear, and encourage them to spend more time improving it.

\subsubsection{External representation of story elements can improve focus on narrative elements}

Our results suggest that when given interface support for narrative tasks young designers seem to focus more on the storytelling aspect of game creation, and make better progress in translating their story ideas into the game. Character creator tools were seen as particularly helpful by young designers, but passive tools which changed the focus of the interface, such as the story map view and the 'Story Elements' panel, are also likely to have had an influence on designers' perceptions of what is important in the game creation activity. Although Narrative Threads active tools were only used for around $6 \%$ of the time, there was a clear difference between the games created by the groups. This suggests that the way the game creation activity is represented in the software is important to the success of a storytelling-focused game creation project.

\section{ACKNOWLEDGMENTS}

We are very grateful to the young people who contributed to the design and took part in the evaluation study. This work was funded through an Engineering and Physical Sciences Research Council (EPSRC) Doctoral Training Account. 


\section{REFERENCES}

1. Burn, A., Writing computer games: Game literacy and newold narratives. Educational Studies in Language and Literature, 2007. 7(4): p. 45-67.

2. Carbonaro, M., M. Cutumisu, H. Duff, S. Gillis, C. Onuczko, J. Siegel, J. Schaeffer, A. Schumacher, D. Szafron, and K. Waugh, Interactive story authoring: A viable form of creative expression for the classroom. Computers \& Education, 2008. 51(2): p. 687-707.

3. Carbonaro, M., M. Cutumisu, M. McNaughton, C. Onuczko, T. Roy, J. Schaeffer, D. Szafron, S. Gillis, and S. Kratchmer. Interactive Story Writing in the Classroom: Using Computer Games. in 2nd International Digital Games Research Conference (DiGRA '05). 2005. Vancouver, Canada.

4. Chatman, S.B., Story and discourse: Narrative structure in fiction and film 1978, Ithaca, NY: Cornell Univ Press.

5. Good, J., Learners at the Wheel: Novice Programming Environments Come of Age. International Journal of PeopleOriented Programming (IJPOP), 2011. 1(1): p. 1-24.

6. Good, J. and J. Robertson, A Multi-Faceted Look at Computer-Based Role-Playing Games Created by Children. Proceedings of Narrative and Interactive Learning Environments, 2004: p. 49-56.

7. Good, J. and J. Robertson. Learning and Motivational Affordances in Narrative-based Game Authoring. in Narrative and Interactive Learning Environments, NILE 2006. 2006. Edinburgh, Scotland.

8. Habgood, M.P.J. and S.E. Ainsworth, Motivating children to learn effectively: exploring the value of intrinsic integration in educational games. The Journal of the Learning Sciences, 2011. 20(2): p. 169-206.

9. Howland, K. Designing an interface for multimodal narrative creation. in CHI 2011 extended abstracts on Human factors in computing systems, May 7-12, 2011. 2011. ACM.

10. Howland, K. Narrative Threads: supporting young people in developing writing skills through narrative-based game creation. 2012. PhD Thesis, University of Sussex, available at: http://sro.sussex.ac.uk/id/eprint/42603

11. Howland, K., B. du Boulay, and J. Good, Fostering engaged and directed learning by activity foregrounding and backgrounding, in International Conference on Artificial Intelligence in Education 20092009: Brighton, UK. p. 241248.

12. Howland, K. and J. Good, Learning to communicate computationally with Flip: A bi-modal programming language for game creation. Computers \& Education, 2015. 80(0): p. 224-240.

13. Howland, K., J. Good, and B. du Boulay. A Game Creation Tool which Supports the Development of Writing Skills: Interface Design Considerations. in Narrative and Interactive Learning Environments (NILE 08). 2008. Edinburgh, UK.

14. Howland, K., J. Good, and B. du Boulay, Narrative Threads: A Tool to Support Young People in Creating Their Own Narrative-Based Computer Games, in Transactions on Edutainment $X$ 2013, Springer. p. 122-145.

15. Howland, K., J. Good, and J. Robertson. A Learner-Centred Design Approach to Developing a Visual Language for
Interactive Storytelling. in Sixth International Conference for Interaction Design and Children (IDC 2007). 2007. Aalborg, Denmark.

16. Jenkins, H., Game design as narrative architecture, in First Person, P. Harrington and N. Frup-Waldrop, Editors. 2004, MIT Press: Cambridge. p. s3, p.118-130.

17. Kafai, Y.B., Minds in Play: Computer Game Design as a Context for Children's Learning1995: Lawrence Erlbaum Assoc Inc.

18. Kafai, Y.B., M.L. Franke, C.C. Ching, and J.C. Shih, Game Design as an Interactive Learning Environment for Fostering Students' and Teachers' Mathematical Inquiry. International Journal of Computers for Mathematical Learning, 1998. 3(2): p. 149-184.

19. Mayer, R.E. and R. Moreno, Nine Ways to Reduce Cognitive Load In Multimedia Learning. Educational Psychologist, 2003. 38: p. 43-52.

20. Norman, D.A., Things that make us smart1993: AddisonWesley Pub. Co Reading, Mass.

21. Overmars, M., Teaching computer science through game design. Computer, 2004. 37(4): p. 81-83.

22. Papert, S., The children's machine: rethinking school in the age of the computer1993: Basic Books, Inc. New York, NY, USA.

23. Pajares, F., Valiante, G. and Cheong, YF. "Writing SelfEfficacy and Its Relation to Gender, Writing Motivation and Writing Competence: A Developmental Perspective." Writing and motivation (2006): 141.

24. Repenning, A., D. Webb, and A. Ioannidou, Scalable game design and the development of a checklist for getting computational thinking into public schools, in Proceedings of the 41st ACM technical symposium on Computer science education2010, ACM: Milwaukee, Wisconsin, USA.

25. Robertson, J. and J. Good, Children's narrative development through computer game authoring, in Interaction Design And Children2004: Washington DC, USA. . p. 57-64.

26. Robertson, J. and J. Good, Children's narrative development through computer game authoring. TechTrends, 2005. 49(5): p. 43-59.

27. Robertson, J. and J. Good. Supporting the Development of Interactive Storytelling Skills in Teenagers. in Technologies for E-Learning and Digital Entertainment, First International Conference, Edutainment 2006 LNCS. 2006. Hangzhou, China: Springer.

28. Robertson, J. and C. Howells, Computer game design: Opportunities for successful learning. Computers \&amp; Education, 2008. 50(2): p. 559-578.

29. Robertson, J. and K. Nicholson. Adventure Author: a learning environment to support creative design. in Sixth International Conference for Interaction Design and Children (IDC 2007). 2007. Aalborg, Denmark.

30. Szafron, D., M. Carbonaro, M. Cutumisu, S. Gillis, M. McNaughton, C. Onuczko, T. Roy, and J. Schaeffer, Writing Interactive Stories in the Classroom. Interactive Multimedia Electronic Journal of Computer-Enhanced Learning (IMEJ), 2005. 7(1): p. 13. 